\title{
II.-ON THE NATURE OF TRUTH.
}

\author{
By the Hon. Bertrand Russell.
}

I.

IN any inquiry into the nature of truth, two questions meet us on the threshold: (1) In what sense, if any, is truth dependent upon mind? (2) Are there many different truths, or is there only the Truth? These two questions are largely interconnected, and it is more or less optional whether we begin with the first or with the second. But, on the whole, the second, namely, the question whether we ought to speak of truths or of the Truth, seems the more fundamental, and the bulk of the present paper will be occupied with this question. The view that truth is one may be called "logical monism"; it is, of course, closely connected with ontological monism, i.e., the doctrine that Reality is one. My paper will consist of three parts. In the first, I shall state the monistic theory of truth, sketching the philosophy with which it is bound up, and shall then consider certain internal difficulties of this philosophy, which suggest a doubt as to the axioms upon which the philosophy is based. In the second part, I shall consider the chief of these axioms, namely the axiom that relations are always grounded in the natures of their terms, and I shall try to show that there are no reasons in favour of this axiom, and strong reasons against. it. In the third part, I shall very briefly indicate the kind of theory, as to the nature of truth, which results from rejection of the axiom that relations are always grounded in the natures of their terms.*

* I shall throughout often refer to Mr. Joachimi's book, The Nature of Truth (Oxford, 1906), because it gives what seems to me the best recent. statement of certain views which I wish to discuss. I shall refer to this. book as "Joachin. 
"That the truth itself," Mr. Joachim says, "is one, and whole, and complete, and that all thinking moves within its recognition and subject to its manifest authority; this I have never doubted" (p. 178).

This doctrine, which is one of the foundation-stones of monistic idealism, has a sweep which might not be obvious at once. It means that nothing is wholly true except the whole truth, and that what seem to be isolated truths, such as $2+2=4$, are really only true in the sense that they form part of the system which is the whole truth. And even in this sense, isolated truths are only more or less true; for when artificially isolated they are bereft of aspects and relations which make them parts of the whole truth, and are thus altered from what they are in the system. If account were taken of all the relations of a certain partial truth to other partial truths, we should be brought to the whole system of truth, and thus the partial truth from which we started would have developed into the one absolute truth. The truth that a certain partial truth is part of the whole is a partial truth, and thus only partially true ; hence we can never say with perfect truth "this is part of the Truth." Hence there can be no sense of truth which is completely applicable to a partial truth, because everything that can be said about a partial truth is only a partial truth.

The whole of truth, or indeed whatever is genuinely a whole, is an organic unity or significant whole, i.e., it is "such that all its constituent elements reciprocally involve one another, or reciprocally determine one another's being as contributory features in a single concrete meaning" (Joachim, p. 66). This is an obvious consequence of the view that only the whole of truth is quite true; for, if this is the case, the truth about any part of the whole must be the same as the whole truth; thus the complete truth about any part is the same as the complete truth about any other part, since each is the whole of truth.

The position which I have been trying to represent is always considered, by those who hold it, a very difficult one to 
apprehend; so much so that the word "crude" has been consecrated to those arguments and philosophies which do not accept this position. As I believe that the more "crude" a philosophy is, the nearer it comes to being true, I cannot hope to persuade idealists that I have understood their position; I can only assure them that $I$ have done my best.

There are in the above theory-so it seems to me-certain intrinsic difficulties which ought to make us suspicious of the premises from which it follows. The first of these difficultiesand it is one which is very candidly faced by Mr. Joachim-is that, if no partial truth is quite true, it cannot be quite true that no partial truth is quite true; unless indeed the whole of truth is contained in the proposition "no partial truth is quite true," which is too sceptical a view for the philosophy we are considering. Connected with this is the difficulty that human beings can never know anything quite true, because their knowledge is not of the whole of truth. Thus the philosophy with which the view in question is bound up cannot be quite true, since, if it were, it could not be known to idealists. And it may be that the elements, in their knowledge, which require correction, are just those which are essential to establishing their view of truth; so long as our premises are more or less faulty, we cannot know that, if corrected, they would give the results we have deduced from them. But this objection-that truth, if it is as alleged, must remain unknowable to us-is met by challenging the distinction between finite minds and Mind. A distinction is necessarily a partial truth; hence, if we distinguish $a$ and $b$, we are only partly right: in another aspect, $a$ and $b$ are identical. Thus, although in a sense we may distinguish our finite knowledge from absolute knowledge, yet in another sense we may say that our knowledge is only real in so far as it is not finite; for the reality of what is finite is the whole of which it is a constituent. Thus we, so far as we are real, do really know all truth; but only idealists know that they know all truth. 
The objections we have just been considering are based upon the difficulty as to what monism means by a whole, and in what sense it conceives that a whole has parts. The uninitiated might imagine that a whole is made up of parts, each of which is a genuine constituent of the whole, and is something on its own account. But this view is crude. The parts of a whole are not self-subsistent, and have no being except as parts. We can never enumerate parts $a, b, c, \ldots$ of a whole $\mathrm{W}$; for the proposition " $"$ is part of $W$ " is only a partial truth, and therefore not quite true. Not only is this proposition not quite true, but the part $a$ is not quite real. Thus $W$ is a whole of parts all of which are not quite real. It follows that $W$ is not quite really a whole of parts. If it is not quite true that $W$ has parts, it cannot be quite true that $\mathrm{W}$ is a whole. In short, the diversity which modern monism tries to synthesise with identity vanishes, leaving reality wholly without structure or complexity of any kind. For though it is essential to its being a whole that it should have parts, it is essential to its being a significant whole that its parts should not quite truly be its parts, since every statement about them, including the statement that they are its parts, must be more or less untrue.

A connected difficulty is the following:-In a "significant whole," each part, since it involves, the whole and every other part, is just as complex as the whole; the parts of a part, in turn, are just as complex as the part, and therefore just as complex as the whole. Since, moreover, the whole is constitutive of the nature of each part, just as much as each part is of the whole, we may say that the whole is part of each part. In these circumstances, it becomes perfectly arbitrary to say that $a$ is part of $\mathrm{W}$ rather than that $\mathrm{W}$ is part of $a$. If we are to say this, we shall have to supplement the monist's notion of whole and part by a more commonplace notion, which I think is really present, though unconsciously, in all monistic thinking; for otherwise the distinction of whole and part 
evaporates, and with it the entire notion of a "significant whole."

Another difficulty of the monistic theory of truth is as to error. Every separate proposition, on the monistic theory, expresses a partial truth: no proposition expresses something quite true, and none expresses something quite false. Under these circumstances, the distinctive characteristic of error cannot lie in the judgment affirmed, since every possible judgment is partially true and partially false. Mr. Joachim, who has considered very carefully the whole question of error, comes to the conclusion-which seems the only possible one for a monistic theory of truth-that the essential characteristic of error is the claim to express truth unqualified (p. 143). He says: "The erring subject's confident belief in the truth of his knowledge distinctively characterises error, and converts a partial apprehension of the truth into falsity" (p. 162). Now this view has one great merit, namely, that it makes error consist wholly and solely in rejection of the monistic theory of truth. As long as this theory is accepted, no judgment is an error; as soon as it is rejected, every judgment is an error. But there are some objections to be urged against this comfortable conclusion. If I affirm, with a "confident belief in the truth of my knowledge," that Bishop Stubbs used to wear episcopal gaiters, that is an error; if a monistic philosopher, remembering that all finite truth is only partially true, affirms that Bishop Stubbs was hanged for murder, that is not an error. Thus it seems plain that Mr. Joachim's criterion does not distinguish between right and wrong judgments as ordinarily understood, and that its inability to make such a distinction is a mark of defect. If a jury, for example, has to decide whether a man has committed a crime, Mr. Joachim's criterion gives no means of distinguishing between a right and a wrong verdict. If the jury remember the monistic philosophy, either verdict is right; if they forget it, either is wrong. What I wish to make plain is, that there 
is a sense in which such a proposition as " $A$ murdered $B$ " is true or false; and that in this sense the proposition in question does not depend, for its truth or falsehood, upon whether it is regarded as a partial truth or not. And this sense, it seems to me, is presupposed in constructing the whole of truth; for the whole of truth is composed of propositions which are true in this sense, since it is impossible to believe that the proposition "Bishop Stubbs was hanged for murder" is part of the whole of truth.

The adherent of the monistic theory of truth may reply that one who remembers this theory will not assert that Bishop Stubbs was hanged for murder, since he will realise that such an assertion would clash with known facts, and would be incapable of fitting into the coherent whole of truth. Now it might be enough to reply that the supposed immunity from errors of fact is not secured by the theory that truth is coherence; since, for example, Hegel was mistaken as to the number of the planets. But this would be an inadequate reply. The true reply is, that we are concerned with the question, not how far a belief in the coherence-theory is a cause of avoidance of error, but how far this theory is able to explain what we mean by error. And the objection to the coherence-theory lies in this, that it presupposes a more usual meaning of truth and falsehood in constructing its coherent whole, and that this more usual meaning, though indispensable to the theory, cannot be explained by means of the theory. The proposition "Bishop Stubbs was hanged for murder" is, we are told, not coherent with the whole of truth, or with experience. But that means, when we examine it, that something is known which is inconsistent with this proposition. Thus what is inconsistent with the proposition must be something true; it may be perfectly possible to construct a coherent whole of false propositions in which "Bishop Stubbs was hanged for murder" would find a place. In a word, the partial truths of which the whole of truth is composed must be such propositions as would 
commonly be called true, not such as would commonly be called false; there is no explanation, on the coherence-theory, of the distinction commonly expressed by the words true and false, and no evidence that a system of false propositions might not, as in a good novel, be just as coherent as the system which is the whole of truth.

The answer to this possibility of several coherent systems is an appeal to "experience." Mr. Joachim says (p. 78): "Truth, we said, was the systematic coherence which characterised a significant whole. And we proceeded to identify a significant whole with 'an organised individual experience, self-fulfilling and self-fulfilled.' Now there can be one and only one such experience: or only one significant whole, the significance of which is self-contained in the sense required. For it is absolute self-fulfilment, absolutely self-contained significance, that is postulated ; and nothing short of absolute individuality-nothing short of the completely whole experience-can satisfy this postulate. And human knowledge-not merely my knowledge or yours, but the best and fullest knowledge in the world at any stage of its development-is clearly not a significant whole in this ideally complete sense. Hence the truth, which our sketch described, is-from the point of view of human intelligence -an Ideal, and an Ideal which can never, as such, or in its completeness, be actual as human experience."

This passage introduces two aspects of the monistic theory which we have not yet considered, namely, its appeal to what it calls "experience," and its use of the deus ex machina. Of these, the first, at least, deserves some discussion.

The distinction between knowing something and the something which we know-between, for example, knowing that the pavements are wet, and the actual wetness of the pavementscannot be accepted by the monistic theory of truth, for this theory, as we saw, is compelled to regard all distinctions as only partially valid. The wetness of the pavements and my knowledge of this wetness, like every other pair of apparently distinct 
objects, really exhibit a combination of identity in difference. Thus knowledge is in a sense different from its object, but is also in a sense identical with its object. The sense in which it is identical may be further defined as whatever sense is necessary to refute those who reject the monistic theory of truth.

I will not now consider the main question of the dependence of truth upon experience, which cannot well be discussed except in connection with the theory of relations. I am content for the present to point out an ambiguity in the notion of "experience." The proposition "Bishop Stubbs was hanged for murder" consists of parts given in experience, and put together in a manner which, in other cases, is unfortunately also given in experience. And it is possible to apprehend the proposition, so that in one sense the proposition can be experienced. That is to say, we can have an experience which consists of realising what the proposition is: we can see a picture of Bishop Stubbs dangling from the gallows. Such are the experiences in novel-reading: we do not believe what we read, we merely apprehend it. Thus experience may consist in merely apprehending, not in believing.* When we apprehend the proposition "Bishop Stubbs was hanged for murder," this proposition is, in a sense, a part of our experience; but in another sense, which is that relevant in constructing the whole of truth, we do not experience this proposition, since we are not led to believe it. This distinction shows that experience, in the sense required by $\mathrm{Mr}$. Joachim, consists of apprehension of truth, and that there is much apprehension which, though experience in one sense, is experience in a sense in which what is false can also be experienced. $\dagger$ Thus here, again,

* Cf. Meinong, Veber Annahmen, Leipzig, 1902, passim.

+ This distinction is connected with the question of Floating Ideas, recently discussed by Mr. Bradley in Mind, N.S., No. 60. He argues that the distinction between the real and the imaginary is not absolute, but his argument explicitly assumes what I have called the "axiom of internal relations." $\quad C f .$, e.g., pp. 457, 461. 
cxperience, as user in establishing the monistic theory of truth, is a notion involving a conception of truth other than that which the monistic theory declares to be alone legitimate. For experience is either no help towards constructing the whole of truth, or it is apprehension of the truth of single propositions, which are true in a sense in which their contradictories are not true. But this conclusion, if sound, is fatal to the monistic theory of truth.

As for the deas ex machind, the ideal experience in which the whole of truth is actualised, I will merely observe that he is in general somewhat discredited, and that idealists themselves are rather ashamed of him, as appears by the fact that they never mention him when they can help it, and that when they do, they introduce him with apologetic words, such as "what is true in the end."-as though what is true " in the end" were anything different from what is true.

We have thus the following objections to the monistic theory of truth:-(1) If no partial truth is quite true, this must apply to the partial truths which embody the monistic philosophy. But if these are not quite true, any deductions we may make from them may depend upon their false aspect rather than their true one, and may therefore be erroneous. (2) It is a consequence of the monistic theory that the parts of a whole are not really its parts. Hence there cannot be any genuine whole on this theory, since nothing can be :eally a whole unless it really has parts. (3) The theory is unable to explain in what sense one partial judgment is said to be true and another false, though both are equally partial. (4) In order to prove that there can be only one coherent whole, the theory is compelled to appeal to "experience," which must consist in knowing particular truths, and thus requires a notion of truth that the monistic theory caunot admit.

But each of these arguments is of the nature of a reductio ad absurdum. We must now turn to what I believe to be the fundamental assumption of the whole monistic theory, namely, 
its doctrine as to relations. If we can show that this doctrine is groundless and untenable, we shall thereby complete the refutation of the monistic theory.

\section{II.}

The doctrines we have been considering may all be deduced from one central logical doctrine, which may be expressed thus : "Every relation is grounded in the natures of the related terms." Let us call this the axiom of internal relations. It follows at once from this axiom that the whole of reality or of truth must be a significant whole in Mr. Joachim's sense. For each part will have a nature which exhibits its relations to every other part and to the whole; hence, if the nature of any one part were completely known, the nature of the whole and of every other part would also be completely known; while conversely, if the nature of the whole were completely known, that would involve knowledge of its relations to each part, and therefore of the relations of each part to each other part, and therefore of the nature of each part. It is also evident that, if reality or truth is a significant whole in Mr. Joachim's sense, the axiom of internal relations must be true. Hence the axiom is equivalent to the monistic theory of truth.

Further, assuming that we are not to distinguish between a thing and its "nature," it follows from the axiom that nothing can be considered quite truly except in relation to the whole. For if we consider " $A$ is related to $B$," the $A$ and the $B$ are also related to everything else, and to say what the $A$ and the $\mathbf{B}$ are would involve referring to everything else in the universe. When we consider merely that part of A's nature in virtue of which $A$ is related to $B$, we are said to be considering $A q u \hat{a}$ related to $B$; but this is an abstract and only partially true way of considering $A$, for $A$ 's nature, which is the same thing as $\mathbf{A}$, contains the grounds of its relations to everything else as well as to $B$. Thus nothing quite true can be said about $A$ short of taking account of the whole universe; and then what is 
said about $A$ will be the same as what would be said about anything else, since the natures of different things must, like those of Leibniz's monads, all express the same system of relations.

Let us now consider more closely the meaning of the axiom of internal relations and the grounds for and against it. We have, to begin with, two possible meanings, according as it is held that every relation is really constituted by the natures of the terms or of the whole which they compose, or merely that every relation has a ground in these natures. I do not observe that idealists distinguish these two meanings; indeed, speaking generally, they tend to identify a proposition with its consequences, * thus embodying one of the distinctive tenets of pragmatism. The distinction of the two meanings is, however, less important than it would otherwise be, owing to the fact that both meanings lead, as we shall see, to the view that there are no relations at all.

The axiom of internal relations in either form involves, as Mr. Bradley has justly urged, $\uparrow$ the conclusion that there are no relations and that there are not many things, but only one thing. (Idealists would add: in the end. But that only means that the consequence is one which it is often convenient to forget.) This conclusion is reached by considering the relation of diversity. For if there really are two things, $A$ and $B$, which are diverse, it is impossible wholly to reduce this diversity to adjectives of $A$ and $B$. It will be necessary that $A$ and $B$ should have different adjectives, and the diversity of these adjectives cannot, on pain of an endless regress, be interpreted as meaning that they in turn have different adjectives. For if we say that $A$ and $B$ differ when $A$ has the adjective "different from $B$ " and $B$ has the adjective "different from $A$,"

* Cf., e.g., Joachim, p. 108.

+ Cf. Appearance and Reality, 2nd ed., p. 519: "Reality is one. It must be single, because plurality, taken as real, contradicts itself. Plurality implies relations, and, through its relations, it unwillingly asserts always a superior unity:" 
we must suppose that these two adjectives differ. Then "different from $A$ " must have the adjective "different from "different from B," which must differ from "different from 'different from A,'" and so on ad infinitum. We cannot take "different from $B$ " as an adjective requiring no further reduction, since we must ask what is meant by "different" in this phrase, which, as it stands, derives an adjective from a relation, not a relation fron an acljective. Thus, if there is to be any diversity, there must be a diversity not reducible to difference of adjectives, i.e., not grounded in the "natures" of the diverse terms. Consequently, if the axiom of internal relations is true, it follows that there is no diversity, and that there is only one thing. Thus the axiom of internal relations is equivalent to the assumption of ontological monism and to the denial that there are any relations. Wherever we seem to have a relation, this is really an adjective of the whole composed of the terms of the supposed relation.

The axiom of internal relations is thus equivalent to the assumption that every proposition has one subject and one predicate. For a proposition which asserts a relation must always be reduced to a subject-predicate proposition concerning the. whole composed of the terms of the relation. Proceeding in this way to larger and larger wholes, we gradually correct our first crude abstract judgments, and approximate more and more to the one truth about the whole. The one final and complete truth must consist of a proposition with one subject, namely, the whole, and one predicate. But since this involves distinguishing subject from predicate, as though they could be diverse, even this is not quite true. The best we can say of it is, that it is not "intellectually corrigible," i.e., it is as true as any truth can be; but even absolute truth persists in being not quite true.*

* Cf. Appearance and Reality, lst ed., p. 544: "Even absolute truth seems thus to turn out in the end to be erroneous. And it must be 
If we ask ourselves what are the grounds in favour of the axiom of internal relations, we are left in doubt by those who believe in it. Mr. Joachim, for example, assumes it throughout, and advances no argument in its favour.* So far as one can discover the grounds, they seem to be two, though these are perhaps really indistinguishable. There is first the law of sufficient reason, according to which nothing can be just a brute fact, but must have some reason for being thus and

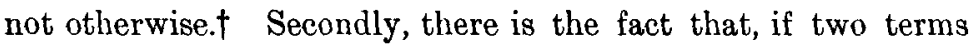
have a certain relation, they cannot but have it, and if they did not have it they would be different; which seems to show that there is something in the terms themselves which leads to their being related as they are.

(1) The law of sufficient reason is hard to formulate precisely. It cannot merely mean that every true proposition is logically deducible from some other true proposition, for this is an obvious truth which does not yield the consequences demanded of the law. For example, $2+2=4$ can be deduced from $4+4=8$, but it would be absurd to regard $4+4=8$ as a reason for $2+2=4$. The reason for a proposition is always expected to be one or more simpler propositions. Thus the law of sufficient reason should mean that every proposition can be deduced from simpler propositions. This seems obviously false, but in any case it cannot be relevant in considering idealism, which holds propositions to be less

admitted that, in the end, no possible truth is quite true. It is a partial and inadequale translation of that which it professes to give bodily. And this internal discrepancy belongs irremovably to truth's proper character. Still, the difference, drawn between absolute and finite truth, must none the less be upheld. For the former, in a word, is not intellectually corrigible."

* See Mind, October, 1906, pp. 530-1.

+ Cf. Appearance and Reality, 2nd ed., p. 575: "If the terms from their own inner nature do not enter into the relation, then, so far as they are concerned, they seem related for no reason at all, and, so far as they are concerned, the relation seems arbitrarily made." Cf. also p. 577. 
and less true the simpler they are, so that it would be absurd to insist on starting from simple propositions. I conclude, therefore, that, if any form of the law of sufficient reason is relevant, it is rather to be discovered by examining the second of the grounds in favour of the axiom of relations, namely, that related terms cannot but be related as they are.

(2) The force of this argument depends in the main, I think, upon a fallacious form of statement. "If A and B are related in a certain way," it may be said, "you must admit that if they were not so related they would be other than they are, and that consequently there must be something in them which is essential to their being related as they are." Now if two terms are related in a certain way, it follows that, if they were not so related, every imaginable consequence would ensue. For, if they are so related, the hypothesis that they are not so related is false, and from a false hypothesis anything can be deduced. Thus the above form of statement must be altered. We may say: "If $A$ and $B$ are related in a certain way, then anything not so related must be other than $\mathrm{A}$ and $\mathrm{B}$, bence, etc." But this only proves that what is not related as $A$ and $B$ are must be numerically diverse from $A$ or $B$; it will not prove difference of adjectives, unless we assume the axiom of internal relations. Hence the argument has only a rhetorical force, and cannot prove its conclusion without a vicious circle.

It remains to ask whether there are any grounds against the axiom of internal relations. The first argument that naturally occurs to an opponent of this axiom is the difficulty of actually carrying it out. We have had one instance of this already as regards diversity; in many other instances, the difficulty is even more obvious. Suppose, for example, that one volume is greater than another. One may reduce the relation "greater than" between the volumes to adjectives of the volumes, by saying that one is of such and such a size and the other of such and such another size. But then the 
one size must be greater than the other size. If we try to reduce this new relation to adjectives of the two sizes, the adjectives must still have a relation corresponding to "greater than," and so on. Hence we cannot, without an endless regress, refuse to adinit that sooner or later we come to a relation not reducible to adjectives of the related terms. This argument applies especially to ail asymmetrical relations, i.e., to such as, when they hold between $\mathrm{A}$ and $\mathrm{B}$, do not hold between $B$ and $A .^{*}$

A more searching argument against the axiom of internal relations is derived from a consideration of what is meant by the "nature" of a term. Is this the same as the term itself, or is it different? If it is different, it must be related to the term, and the relation of a term to its nature cannot, without an endless regress, be reduced to something other than a relation. Thus if the axiom is to be adhered to, we must suppose that a term is not other than its nature. In that case, every true proposition attributing a predicate to a subject is purely analytic, since the subject is its own whole nature, and the predicate is part of that nature. But in that case, what is the bond that unites predicates into predicates of one subject? Any casual collection of predicates might be supposed to compose a subject, if subjects are not other than the system of their own predicates. If the "nature" of a term is to consist of predicates, and at the same time to be the same as the term itself, it seems impossible to understand what we mean when we ask whether $S$ has the predicate $P$. For this camnot mean: "Is $\mathrm{P}$ one of the predicates enumerated in explaining what we mean by $S$ ?" and it is hard to see what else, on the view in question, it could mean. We cannot attempt to introduce a relation of colerence between predicates, in virtue of which they may be called predicates of one

* The argument which is nerely indicated above, is set forth fully in my Principles of Mathematics, ş 212-216. 
subject; for this would base predication upon a relation, instead of reducing relations to predications. Thus we get into equal difficulties whether we affirm or deny that a subject. is other than its " nature."*

Again, the axiom of internal relations is incompatible with all complexity. For this axiom leads, as we saw, to a rigid monism. There is only one thing, and only one proposition. The one proposition (which is not merely the only true proposition, but the only proposition) attributes a predicate to the one subject. But this one proposition is not quite true, because it involves distinguishing the predicate from the subject. But then arises the difficulty: if predication involves difference of the predicate from the subject, and if the one predicate is not distinct from the one subject, there cannot, even, one would suppose, be a false proposition attributing the one predicate to the one subject. We shall have to suppose, therefore, that predication does not involve difference of the predicate from the subject, and that the one predicate is identical with the one subject. But it is essential to the philosophy we are examining to deny absolute identity, and retain "identity in difference." The apparent multiplicity of the real world is otherwise inexplicable. The difficulty is that "identity in difference" is impossible, if we adhere to strict monism. For "identity in difference" involves many partial truths, which combine, by a kind of mutual give and take, into the one whole of truth. But the partial truths, in a strict monism, are not merely not quite true: they do not subsist at all. If there were such propositions, whether true or false, that would give plurality. In short, the whole conception of "identity in difference" is incompatible with the axiom of internal relations; yet without this conception, monism can give no account of the world, which suddenly collapses like an opera-hat. I conclude that the axiom is false, and that

* On this subject, ff. my Philosophy of Leibniz, $§ \S 21,24,25$, 
those parts of idealism which depend upon it are therefore groundless.

There would seem, therefore, to be reasons against the axiom that relations are necessarily grounded in the "nature" of their terms or of the whole composed of the terms, and there would seem to be no reason in favour of this axiom. When the axiom is rejected, it becomes meaningless to speak of the "nature" of the terms of a relation: relatedness is no longer a proof of complexity, a given relation may hold between many different pairs of terms, and a given term may have many different relations to different terms. "Identity in difference" disappears: there is identity and there is difference, and complexes may have some elements identical and some different, but we are no longer obliged to say of any pair of objects that may be mentioned that they are both identical and different- " in a sense," this "sense " being something which it is vitally necessary to leave undefined. We thus get a world of many things, with relations which are not to be deduced from a supposed " nature" or scholastic essence of the related things. In this world, whatever is complex is composed of related simple things, and analysis is no longer confronted at every step by an endless regress. Assuming this kind of world, it remains to ask what we are to say concerning the nature of truth.

\section{III.}

Having now decided that relations are not grounded in the nature of their terms, we have no longer any reason for supposing that "experiencing makes a difference to the facts." The rejection of this supposition is regarded by Mr. Joachim (p. 33) as the essence of the position which he is attacking; ${ }^{*}$ it is, however, only a consequence of the theory of relations.

* He is careful to point out that he does not attribute this view to Mr. Moore or to me. 
But from the point of view of the theory of truth, it is a very important consequence, since it sets facts and our knowledge of them in two different spheres, and leaves the facts completely independent of our knowledge. One might, it is true, have started by arguing that facts, if they are facts, must be independent of knowledge, since knowledge is of the nature of discovery rather than of creation. But it would be impossible to answer monistic objections to this argument without examining the nature of relations; hence the question as to the nature of relations is more fundamental than that as to the dependence of facts upon knowledge.

When we entertain a correct belief, that which we believe may be called a fact. A fact is always complex: thus when we perceive that something exists, the something is not a fact, but its existence is a fact. If $A$ exists, "A's existence" is a fact; perception consists in the apprehension of such facts. Similarly $2+2$ is not a fact; but it is a fact that $2+2=4$. Given any related objects, these objects in relation form a complex object, which may be called a fact; and when we apprehend this fact, we have knowledge. Truth, then, we might suppose, is the quality of beliefs which have facts for their objects, and falsehood is the quality of other beliefs. And a fact may be defined as whatever there is that is complex.

But this simple view is rather difficult to defend against objections of various kinds, tending to show that there are not only mistaken beliefs, but also non-facts, which are the objectively false objects of mistaken beliefs. The main reason for this view is the difficulty of answering the question: "What do we believe when our belief is mistaken?"

The view that truth is the quality of belief in facts, and falsehood the quality of other belief's, is a form of the correspondence theory, i.e., of the theory that truth means the correspondence of our ideas with reality. And the correspondence theory, as Mr. Joachim justly contends, involves the consequence that 
error is belief in nothing.* For, when we believe truly, our belief is to have an object which is a fact, but when we believe falsely, it can have no object, unless there are objective nonfacts. The people who believe that the sun goes round the earth seem to be believing something, and this something cannot be a fact. Thus, if beliefs always have objects, it follows that there are objective non-facts.

This argument would be conclusive, I think, if it were certain that a belief can be validly regarded as a single state of mind. There are, however, difficulties in so regarding a belief. The chief of these difficulties is derived from paradoxes analogous to that of the liar, e.g., from the man who believes that all his beliefs are mistaken, and whose other beliefs are certainly all mistaken. If he is mistaken in this belief, then all his beliefs are mistaken, which is what he is believing; therefore he is not mistaken; therefore he is right in believing that all his beliefs are mistaken, and therefore this belief is mistaken. We can escape this paradox if a belief cannot be validly treated as a single thing. $\dagger$ Thus a belief, if this view is adopted, will not consist of one idea with a complex object, but will consist of several related ideas. That is, if we believe (say) that $A$ is $B$, we shall have the ideas of $A$ and of $B$, and these ideas will be related in a certain manner; but we shall not have a single complex idea which can be described as the idea of "A is B." A belief will then differ from an idea or presentation by the fact that it will consist of several interrelated ideas. Certain ideas standing in certain relations will be called the belief that so-and-so. In the event of the objects of the ideas standing in the correspondingf relation, we shall say that the

* P. 129. "Thinking of nothing" is Mr. Joachim's phrase. This is not quite applicable to the above form of the correspondence theory, but "belief in nothing" is strictly applicable.

t The line of argument required is explained in "Les paradoxes de $1 x$ logique," Revue de Métaphysique et de Morale, September, 1906.

\$ There is great difficulty in explaining what this correspondence consists of, since, for example, the belief that $A$ and $B$ have the relation 
belief is true, or that it is belief in a fact. In the event of the objects not standing in the corresponding relation, there will be no objective complex corresponding to the belief, and the belief is belief in nothing, though it is not "thinking of nothing," because it is thinking of the objects of the ideas which constitute the belief. Thus it would seem that the argument that false beliefs must be beliefs in something is not conclusive in favour of objective falsehood."

The view that a belief is a complex of ideas, not a single idea, has the merit of distinguishing between the perception of a fact and the judgment which affirms the same fact. We may look at the sky and perceive the sun shining; we may then proceed to judge that "the sun is shining." The same fact, in this case, is first perceived and then judged; the question is: How can the perception and the judgment differ? We may reply that, in the perception, the actual fact or objective complex is before the mind, i.e., there is a single state of mind which has the said objective complex for its object, while in the belief, there is merely a complex of presentations of constituents of the objective complex, these presentations being related in a manner corresponding to that in which the constituents of the objective complex are related. This distinction between perception and judgment is the same as the distinction between intuition and discursive knowledge. The above theory has the merit of explaining the puzzling fact that perceptions, though they are not judgments, may nevertheless give grounds for judgments.

There is, however, another argument in favour of objective

$R$ must be a threo-term relation of the ideas of $A$ and $B$ and $R$. Whether a satisfactory definition of the required correspondence is possible, I do not know.

* I do not wish positively to advocate the above theory of belief, which may very likely be open to fatal objections. I merely wish to suggest its possibility. On the subject of the apprehension of complexes, which is closely connected with our present subject, see Rudolf Ameseder, "Ueber Vorstellungsproduktion," in Untersuchungen zur Gegenstandstheorie und Psychologic, edited by Meinong, Leipzig, 1904. 
falsehood, derived from the case of true propositions which contain false ones as constituent parts. Take, e.g., "Either the earth goes round the sun, or it does not." This is certainly true, and therefore, on the theory we are considering, it represents a fact, i.e., an objective complex, which is not constituted by our apprehension of it. But it is, at least apparently, compounded of two (unasserted) constituents, namely: "The earth goes round the sun," and "the earth does not go round the sun," of which one must be false. Thus our fact seems to be composed of two parts, of which one is a fact, while the other is an objective falsehood.

If this argument is to be rejected, it can only be on the ground that, given a fact, it cannot always be validly analysed into subordinate related complexes, even when such analysis seems possible. A valid analysis, we shall have to contend, must break up any apparent subordinate complexes into their constituents, except when such complexes are facts.* For in all other cases, there is no such subordinate complex as language appears to suggest. Here again, as with the previous objection, the answer, though not obviously wrong, is difficult, and leaves only a doubt, not a certainty.

If we accept the view that there are objective falseloods, we shall oppose them to facts, and make truth the quality of facts, falsehood the quality of their opposites, which we may call fictions. Then facts and fictions together may be called propositions. A belief always has a proposition for its object, and is knowledge when its object is true, error when its object is false. Truth and falsehood, in this view, are ultimate, and no account can be given of what makes a proposition true or false.

If we reject objective falsehood, we have, apart from belief,

* This is an extension of the principle applied in my article, "On Denoting" (Mind, October, 1905), where it is pointed ont that such propositions as "the King of France is bald" contain no constituent corresponding to the phrase "tlie King of France." 
only facts. Beliefs are then complexes of idcas, to which complexes of the objects of the ideas may or may not correspond. When they do correspond, the beliefs are true, and are beliefs in facts; when they do not, the beliefs are erroneous, and are beliefs in nothing. On this view we may say that perception, unlike belief, apprehends the fact itself, and thus may, without being belief, be a valid ground of belief. This would account further for the infallibility of perception ; but it may be doubted whether this is a merit, since it may well be questioned whether perception is infallible.

As between the above two views of truth, I do not at present see how to decide. The view which denies objective falsehoods is, on the face of it, more plausible; but the difficulties in its way are formidable, and may turn out to be insuperable.

We may now sum up our whole discussion. We found first that the belief that only the whole truth is wholly true leads us into certain difficulties, which seem to show that any premises from which this belief follows, must be erroneous. We then examined one premise from which this belief follows, namely, the axiom that relations are grounded in the nature of their terms, and we saw reason to reject this axiom. Finally, we considered what will be the nature of truth on the view which admits many truths. We found that two theories seem tenable, one of which regards truth as the quality of beliefs which are beliefs in facts, which are the only non-mental complexes, while the other regards truth and falsehood as both capable of belongings to non-mental complexes, which we called propositions, of which there are two kinds, facts, which are true, and fictions, which are false. Between these views, the decision is to be made, it would seem, by considerations of detail, as to the result of which it would be rash to decide hastily. 